PEMBELAJAR: Jurnal Ilmu Pendidikan, Keguruan, dan Pembelajaran

Volume 1 Nomor 1 April 2017 hal 9-16

e-ISSN: 2549-9114 dan p-ISSN: 2549-9203

(Received: Februari-2017; Reviewed: Maret-2017; Published: April 2017)

\title{
Pengaruh Profesional Dosen Terhadap Kualitas Pembelajaran Dosen Agama Islam Di Fakultas Keguruan Ilmu Pendidikan Universitas Pattimura
}

\author{
Husaini \\ Politeknik Negeri Ambon \\ Email: arifinhusaini@yahoo.co.id
}

\begin{abstract}
Abstrak: penelitian ini bertujuan untuk mengetahui: (1) Apakah kompetensi profesional dosen berpegaruh terhadap kualitas pembelajaran dosen PAI, dan (2) Seberapa besar pengaruh kompetensi profesional dosen terhadap kualitas pembelajaran dosen PAI. Metode penelitiannya menggunakan pendekatan kuantitatif melalui observasi dan sebaran angket sebagai alat pengumpulan data, jumlah sampel sebanyak 94 mahasiswa yang pernah mengikuti perkuliahan pendidikan agama Islam di Fakultas Keguruan Ilmu Pendidikan. Hasil penelitian adalah: (1) Kompetensi profesional yang dimiliki dosen PAI memberikan pengaruh terhadap kualitas pembelajaran dosen PAI, dan (2) Besarnya pengaruh kompetensi dosen PAI terhadap kualitas pembelajaran dosen PAI, meliputi (a) sumbangan relative berdasarkan kuesioner yang memberikan respon "cukup" sebesar 68,36\% kompetensi profesional, dan (b) sumbangan efektif berdasarkan kuesioner yang memberikan respon "baik/kompeten" sebesar 49,93\% kompetensi profesional.
\end{abstract}

Kata Kunci: Kompetensi dosen, profesional, kualitas pembelajaran, dan pendidikan agama Islam.

\begin{abstract}
This aims to knows : 1) whether the professional competence of lecturers affect on learning quality of islamic lecturers, 2) how much the influenceof pedagogical and professional competence of lecturers on the learning quality of Islamic lecturers. The research method with the quantitative approach through the observation and distribution of a questionnaire as a data collection tool, the total sample of 94 students who had attended the study of Islamic education in teachering and education facultyin Pattimura University. The study are : 1) professional competence possessed by Islamic lecturersgive the influence on learning qualityof Islamic lecturers, 2) the effect of the competence of Islamic lecturers on learning quality ofIslamic lecturers, include a) contributions relative based on a questionnaire that gives response "adequate" amount $68,36 \%$ of professional competence, and also effective contribution based on questionnaires responded "good / 49,93\% of professional competence.
\end{abstract}

Keywords: Lecture Competence, Professional, Quality Learning, and Education of Islamic

(C)2017 -Pembelajar Universitas Negeri Makassar. Ini adalah artikel dengan akses terbuka dibawah licenci CC BY-NC-4.0 (https://creativecommons.org/licenses/by-nc/4.0/ ).

\section{PENDAHULUAN}

Merujuk pada UU Nomor 20 Tahun 2003 tentang sistem pendidikan nasional, UU Nomor 14 Tahun 2005 tentang guru dan dosen dan PP No 19 Tahun 2005, tentang standar nasional pendidikan mengamanatkan bahwa "Pendidikan nasional berfungsi mengembangkan kemampuan dalm membentuk watak serta peradaban bangsa yang bermartabat dalam rangka mencerdaskan bangsa, kehidupan bangsa, bertujuan untuk berkembangnya potensi mahasiswa agar menjadi manusia yang beriman dan bertakwa kepada Tuhan yang Maha Esa, berakhlak mulia, sehat berilmu, cakap, kreatif, mandiri dan menjadi warga negara yang demokratis dan bertanggung jawab". Penelitian yang dilakukan oleh Syaikhul Alim (Dosen UISA, Semarang, 
2012) yakni "pengaruh kualifikasi pendidikan, keikutsertaan diklat dan sikap pada profesi terhadap kompeten tenaga pendidik", hasilnya terdapat pengaruh baik individu maupun bersama-sama dari kualifikasi pendidikan, keikutsertaan diklat dan sikap pada profesi terhadap kompetensi tenaga pendidik.

Dosen sebagai salah satu sumber daya manusia yang memilki peran yang cukup penting dalam proses pendidikan. Beberapa hal yang perlu diperhatikan dalam memberi perhatian terhadap dosen adalah kompetensi profesinal serta kualitas Pembelajaran dosen. Standar kompetensi yang diperlukan seorang dosen dalam menjalankan pekerjaannya mengharuskan dosen untuk menguasai kurikulum, menguasai materi pembelajaran, memahami kebijakan-kebijakan pendidikan, pemahaman pada karakteristik dan isi bahan pembelajaran, menguasai konsepnya, memahami konteks ilmu tersebut dengan masyarakat dan lingkungan, memahami bagaimana dampak dan realasi ilmu tersebut dalam kehidupan masyarakat dengan ilmu yang lain.

Sebagai seorang pendidik, dosen harus memenuhi beberapa syarat khusus. Untuk menjadi dosen harus belajar mempersonalisasikan beberapa sikap yang dibekali dengan berbagai ilmu pendidikan sebagai dasar yang menyatu dalam diri menjadi seorang pribadi khusus yang akan mentransformasikan pada mahasiswanya, sehingga mampu membawa perubahan dalam tingkah laku mahasiswanya. Dosen sebagai tenaga pendidik dalam pelaksanaan pembelajaran terhadap mahasiswa juga harus memiliki mutu yang tinggi untuk mencapai tujuan dalam proses pembelajaran. Nilai keberhasilan pendidikan sangat tergantung dari mutu pengajarnya. (Abdurrahman, Pengelolaan Pengajaran ; Cet. V; Ujung Pandang: Bintang Selatan, 1994), h. 45 - 50. Penelitian yang dilakukan oleh Hanafiah misalnya mengungkapkan bahwa tercapai tidaknya mutu pendidikan tinggi yang diharapkan, ditentukan oleh mutu para dosen di setiap bidang ilmu yang dibinanya. penelitian lain menyatakan, mutu pendidikan bergantung pada mutu personel pengajar atau the man behind the sun.

Akreditas yang diperoleh Unpatti sebagai salah satu ikon mutu pendidikan tinggi negeri yang ada di Kota Ambon yang mencerminkan standar pendidikan di wilayah ini. Untuk menunjang standar pendidikan tersebut, salah satunya harus ditunjang dengan dosen yang berkualifikasi sesuai dengan bidang keilmuannya. Tenaga dosen merupakan motor pengerak dalam dunia pendidikan, karena tenaga dosen secara langsung dapat mempengaruhi dan membina serta mengembangkan kemampuan potensi mahasiswa agar menjadi manusia yang cerdas terampil dan bermoral. (Nana Sudjana, Cara Belajar Aktif dan Proses Belajar Mengajar ; Cet. III; Bandung: Sinar Baru, 1996), h. 47. Sebagai pendidik, dosen dapat memberikan contoh yang terbaik terhadap mahasiswanya supaya mampu memiliki kharisma dan menjunjung tinggi nilai moral dan kode etik seorang dosen. Penelitian yang dilakukan oleh Kusumastuti mengenai kompetensi antara lain: (1) orientasi untuk berprestasi; (2) perhatian terhadap kerapian, mutu, dan ketelitian; (3) inisiatif; (4) pencarian dan pengumpulan informasi.

Kompetensi dosen, di antaranya mencakup kompetensi profesional dosen PAI di FKIP Universitas Pattimura Ambon sebagai lokasi penelitian, dari hasil pengamatan menunjukkan bahwa hanya dua orang dosen PAI sebagai tenaga pengajar melakukan proses pembelajaran yang ditujukan pada mahasiswa beragama Islam, ternyata kompetensi realitas sosial tersebut, mempengaruhi juga dengan kompetensi profesional dosen PAI dalam melakukan proses pembelajaran, di antaranya kurangnya mahasiswa terlibat dalam kajiankajian keagamaan di kampus, dan dosen juga kurang memiliki kemampuan untuk melakukan penelitian, akhirnya proses pembelajaran dilakukan bersifat stagnan keilmuan yang disampaikan dan penyampaian ilmu PAI bukan hasil penelitian dan atau fenomena keseharian masyarakat Islam kurang disampaikan dalam proses pembelajaran.

Fenomena kompetensi profesional di atas akan mempengaruhi kualitas pembelajaran dosen PAI di FKIP Unpatti Ambon, terutama dosen PAI kurang memiliki kemampuan dalam menyajikan pengajaran berbasis penelitian yang sesuai dengan perkembangan ilmu pengetahuan PAI. Artinya dosen PAI kurang memberikan pengetahuan baru berbasis realitas social keseharian masyarakat Islam ke Malukuan, khususnya masyarakat Islam di Kota Ambon yang masih mengalami kehidupan sosialkeagamaan yang kurang baik, seperti individu satu dengan lainnya dalam komunitas sendiri 
kurang saling menghormati yang menimbulkan perbedaan di antara keduanya, kesemuanya berdampak kurangnya kerukunan internal mereka.

Peningkatan kualitas dosen harus didasarkan pada kompetensi yang terdapat dalam Undang-undang RI Nomor 14 tahun 2005 tentang Guru dan Dosen adalah sebagai berikut:

"Guru dan Dosen adalah pendidik professional dengan tugas utama mendidik, mengajar, membimbing, mengarahkan, melatih, menilai dan mengevaluasi mahasiswa pada pendidikan anak usia dini jalur pendidikan formal, pendidikan dasar, dan pendidikan menengah dan pendidikan berkelanjutan".

Peningkatan kualitas dosen harus ditunjang dengan penguasaan kompetensi, studi lanjut, sertifikasi, dan pelatihan-pelatihan yang berkenaan dengan peningkatan mutu pendidikan perguruan tinggi Universitas Pattimura Ambon. Penerimaan dosen pendidikan agama islam untuk peningkatan mutu pendidikan perguruan tinggi Universitas Pattimura sangatlah penting hal ini berkenaan dengan tugas dosen benarbenar memberikan kontribusi kepada mahasiswanya secara wajar dan benar, sehingga Universitas Patimura Ambon dapat melahirkan mahasiswa yang berkualitas.

\section{TINJAUAN PUSTAKA}

Dalam kaitannya dengan dosen sebagai pendidik, maka pentingnya dosen yang profesional yang memenuhi standar kualifikasi di atur dalam pasal 8 Undang-undang No 14 tahun 2005 tentang guru dan dosen yang menyebutkan bahwa dosen wajib memilki kualifikasi akademik minimal S1 atau D4, kompetensi, sertifikat pendidik, sehat jasmani dan rohani, serta memilki kemampuan untuk mewujudkan pendifdikan nasional. Lebih dalam lagi pasal 10 ayat 1 UUGD dan pasal 28 ayat 3 PP 19 tahun 2005 tentang Standar Nasional Pendidikan dijelaskan bahwa: Kompetensi Dosen yang dimaksud meliputi: kompetensi pedagogik, kompetensi kepribadian, kompetensi sosial, dan kompetensi profesional.

\section{Peranan dan Tugas Dosen}

Peranan Dosen dalam proses pembelajaran meliputi banyak hal sebagaimana yang dikemukakan oleh Adam dan Dece, antara lain bahwa peranan Dosen adalah: "Sebagai pengajar, pemimpin kelas, pembimbing, pengatur lingkungan, partisipan, ekspeditor, perencana supervisor, motivator, dan konselor."

Zakiah Daradjat berpendapat seperti yang dikutip oleh Pupuh Fathurrahman \& M. Sobry Sutikno dalam bukunya Strategi Belajar Mengajar Melalui Konsep Islam dan Umum (Cet. I; Bandung: PT. Refika Aditama, 2007), $h$. 133. bahwa fungsi Dosen pada dasarnya bisa dibagi ke dalam tiga fungsi utama, yaitu :

(1) Fungsi pengajaran atau Dosen sebagai pengajar.

Sebagai pengajar, Dosen bertugas membina perkembangan pengetahuan, sikap dan keterampilan. Pekerjaan bukan sematamata mengajar melainkan juga harus mengerjakan berbagai hal yang bersangkut paut dengan pendidikan Mahasiswa.

(2) Dosen sebagai pembimbing dan pemberi bimbingan.

Dosen agama dalam memberikan bimbingan meliputi bimbingan belajar dan bimbingan perkembangan sikap keagamaan. Dengan demikian membimbing dimaksudkan agar setiap mahasiswa yang sebenarnya dalam kapasitas belajar dan bersikap. Jangan sampai setiap murid menganggap rendah atau meremehkan kemampuannya sendiri dalam potensinya untuk belajar dan bersikap sesuai dengan ajaran agama Islam.

(3) Dosen sebagai manager.

Dosen bertugas pula sebagai tenaga administrasi, bukan sebagai pegawai kantor, melainkan sebagai pengelolah kelas atau pengelolah (manager) interaksi belajar mengajar.

\section{Kompetensi Dosen}

Kompetensi diartikan sebagai pengetahuan, keterampilan, dan nilai-nilai dasar yang direfleksikan dalam kebiasaan berpikir dan bertindak. Dengan demikian, kompetensi yang dimiliki oleh setiap dosen akan menunjukkan kualitas dosen yang sebenarnya. Menurut UU no. 14 tahun 2005 kompetensi dosen meliputi: kompetensi pedagogik, kepribadian, sosial dan profesional.

\section{Kompetensi Profesional Dosen}

Menurut Undang-undang No 14 tahun 2005 tentang guru dan dosen, Kompetensi profesional merupakan kemampuan penguasaan materi pembelajaran secara luas dan mendalam yang memungkinkannya membimbing mahasiswa memenuhi standar kompetensi yang ditetapkan dalam Standar Nasional Pendidikan. 
Nana Sudjana, Cara Belajar Aktif dan Proses Belajar Mengajar (Cet. III; Bandung: Sinar Baru, 1996), h. 47 menjelaskan hal-hal yang perlu diperhatikan oleh seseorang dosen menjadi kompetensi yang profesional antara lain :

(1) Kemampuan menjelaskan pokok bahasan/topik secara tepat.

(2) Kemampuan memberikan contoh relevan dari konsep yang diajarkan.

(3) Kemampuan menjelaskan keterkaitan bidang/topik yang diajarkan dengan bidang / topik lain.

(4) Kemampuan menjelaskan keterkaitan bidang/topik diajarkan dengan konteks kehidupan.

(5) Penguasaan akan isu-isu mutakhir dalam bidang yang diajarkan.

(6) Penggunaan hasil-hasil penelitian untuk meningkatkan kualitas perkuliahan

(7) Pelibatan mahasiswa dalam penelitian/kajian dan atau pengembangan/ rekayasa/desain yang dilakukan dosen.

(8) Kemampuan menggunakan beragam teknologi komunikasi.

Berdasarkan uraian diatas, hipotesa dapat dikembangkan sebagai berikut:

$\mathrm{H} 2$ : Profesional dosen berpengaruh positif terhadap kualitas pembelajaran dosen PAI

Kualiatas Pembelajaran Dosen
Seorang dosen harus mampu merencanakan kinerjanya yaitu mempersiapkan hal-hal yang akan dikerjakan yang akan datang untuk mencapai suatu tujuan yang telah ditetapkan.

Peningkatan kualitas dosen harus ditunjang dengan penguasaan kompetensi, studi lanjut, sertifikasi, dan pelatihan-pelatihan yang berkenaan dengan peningkatan mutu pendidikan perguruan tinggi.

Menurut Oemar Hamalik, Pendidikan Guru/Dosen Berdasarkan Kompetensi (Cet I; Jakarta: Bumi Aksara, 2002), h. 43, pelaksanaan peran ini menuntut kemampuan tertentu, yaitu:

(1) Mampu dalam menyajikan bahan pengajaran.

(2) Mampu menyusun GBPP/SAP.

(3) Mampu menyampaikan ilmu kepada mahasiswa

(4) Mampu menggairahkan semangat belajar mahasiswa.

(5) Mampu melakukan penilaian terhadap hasil belajar mahasiswa.

(6) Mampu menggunakan bahasa yang baik dan benar.

\section{METODE PENELITIAN}

Kajian penelitian ini bersifat kuantitatif, di mana data diperoleh dari sebaran instrument kuesioner. Dalam penelitian ini ada tiga variabel yang dilibatkan, dua variabel independent dan satu variabel dependent.
Variabel Independent (X)

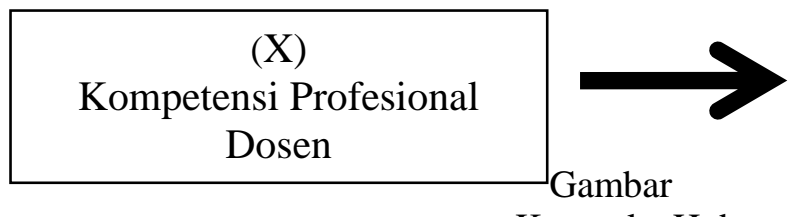

Variabel ini diukur melalui 20 item pertanyaan, dengan opsion jawaban berskala 14. Skor kumulatif yang mungkin diperoleh merentang dari 20 - 80 dengan klasifikasi:

\begin{tabular}{lllc}
$20-35$ & $:$ & Tidak kompeten & \\
-65 & $:$ & Cukup kompeten & \\
$36-50$ & $:$ Kurang kompeten & & 66 \\
$-80 \quad:$ Kompeten & & \\
\multicolumn{3}{c}{ Populasi dalam penelitian ini } & yakni
\end{tabular}
seluruh mahasiswa muslim yang pernah mengikuti perkuliahan pendidikan agama Islam

\section{Variabel Dependent (Y)}

(Y)

Kualitas Pembelajaran Dosen PAI berjumlah 1.557 orang.

Jumlah sampel penelitian ini adalah sebanyak 94 orang mahasiswa muslim dan responden ini terdistribusi secara proporsional.

Untuk menarik sampel dari populasi tersebut digunakan rumus Taro Yamane sebagai berikut:

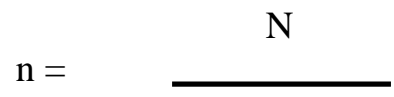




$$
\left(\mathrm{N} \cdot \mathrm{d}^{2}\right)+1
$$

Dimana :

$\mathrm{n}=$ ukuran sampel; $\mathrm{d}=$ presisi yang besarnya ditentukan; $\mathrm{N}=$ ukuran populasi

Presisi yang digunakan dalam penelitian ilmu sosial adalah $10 \%$ sehingga ukuran sampel dapat dihitung sebagai berikut :

$$
\begin{aligned}
& \mathrm{n}=\frac{1.557}{\left(1.557(0,1)^{2}\right)+1} \\
& \mathrm{n}=\frac{1.557}{16,57}=93,96 \text { dibulatkan }=94
\end{aligned}
$$

Uji validitas akan dilakukan dengan metode "Pearson" atau metode "Product Moment", yaitu dengan mengkorelasikan skor butir pada kuesioner dengan skor totalnya. Jika nilai koefisien korelasinya lebih dari 0,3 , maka butir pertanyaan tersebut dapat dikatakan valid. Uji validitas ini menggunakan bantuan program SPSS 16.0 for windows.

Perhitungan Cronbach's Alpha dilakukan dengan menghitung rata-rata interkorelasi di antara butir-butir pertanyaan dalam kuesioner. Variabel dikatakan reliable jika nilai aphanya lebih dari 0,3.

Analisa data yang digunakan dalam penelitian ini adalah analisis statistik deskriptif dan inferensial. Dimana skala Liker diperoleh dari kuesioner/angket jawaban yang diberikan semuanya mempunyai persepsi positif (favorable). Jadi setiap pertanyaan tersebut diberikan 4 jawaban pilihan yang sesuai dengan fokus masalah dalam pertanyaan tersebut. Masing-masing jawaban diberi nilai skor 1 sampai 4.
1. Teknik analisis regresi linier berganda dengan tiga prediktor untuk mengukur dimensi mana yang paling besar pengaruhnya terhadap variabel dependent. Rumus yang digunakan adalah:

Di mana:

$$
\begin{array}{rlr}
\mathrm{Y} & =\text { Kualitas pembelajaran } & \mathrm{a}= \\
& \text { Konstan } & \mathrm{b}= \\
& \text { Koefisien regresi } & \\
\mathrm{X}_{1} & =\text { Kompetensi profesional } &
\end{array}
$$

(2) Uji F, digunakan untuk mengukur tingkat signifikansi hubungan variabel bebas dengan terikat.

(3) Uji t, untuk mengetahui koefisien regresi antara variabel bebas dengan variabel terikat.

\section{HASIL DAN PEMBAHASAN}

Pada pemaparan ini, peneliti akan mengemukakan hasil penelitian yang diperoleh melalui pengumpulan data dari jawaban sebaran angket dan serangkaian analisis data yang akan dilakukan.

\section{Pengujian Pengukuran Penelitian Uji Validitas dan Uji Reliabilitas}

Hasil pengujian validitas terhadap variable kompetensi professional dosen (X2) dengan 14 item pertanyaan dan kualitas pembelajaran dosen PAI (Y) dengan 6 item pertanyaan dinyatakan valid.

Hasil pengujian reliabilitas terhadap kedua variable kompetensi professional dosen (X2) dan kualitas pembelajaran dosen PAI (Y) dinyatakan reliable.

Pengaruh Kompetensi Terhadap Kualitas

\section{Pembelajaran Dosen PAI}

\section{a. Kompetensi Profesional Dosen PAI}

\begin{tabular}{|l|r|r|r|r|}
\hline Model & \multicolumn{1}{|c|}{ R } & R Square & Adjusted R Square & $\begin{array}{c}\text { Std. Error of the } \\
\text { Estimate }\end{array}$ \\
\hline 1 & $.849^{\mathrm{a}}$ & .721 & .718 & .46298 \\
\hline
\end{tabular}

a. Predictors: (Constant), $\mathrm{X}$ 
Berdasarkan angka koefisien korelasi ( $\mathrm{r}$ ) didapat ( $\mathrm{r}_{\text {hitung }} \quad 0,849>0,202 \quad\left(\mathrm{r}_{\text {tabel }}\right)$, tersebut diperoleh nilai koefisien determinasi $\left(\mathrm{r}^{2}\right)$ variabel $\mathrm{X}$, terhadap $\mathrm{Y}$ sebesar $0,849^{2}=0,721$ atau $72,1 \%$. Ini berarti $72,1 \%$ varians yang terjadi pada variabel kualitas pembelajaran (Y) dapat dijelaskan melalui varians yang terjadi pada variabel kompetensi profesional (X).
Dengan demikian berarti pula bahwa perubahan yang terjadi pada variabel $\mathrm{Y}$ dapat dijelaskan oleh perubahan pada variabel $X$. Jadi kesimpulannya "variabel kompetensi profesional berpengaruh positif terhadap kualitas pembelajaran dosen PAI di FKIP Universitas Pattimura Kota Ambon."

\begin{tabular}{|c|c|c|c|c|c|c|}
\hline \multicolumn{7}{|c|}{ Coefficients $^{\mathrm{a}}$} \\
\hline \multirow{2}{*}{\multicolumn{2}{|c|}{ Model }} & \multicolumn{2}{|c|}{ Unstandardized Coefficients } & $\begin{array}{l}\text { Standardized } \\
\text { Coefficients }\end{array}$ & \multirow[b]{2}{*}{$\mathrm{t}$} & \multirow[b]{2}{*}{ Sig. } \\
\hline & & $\mathrm{B}$ & Std. Error & Beta & & \\
\hline 1 & (Constant) & .527 & .141 & & 3.728 & .000 \\
\hline & $\mathrm{X} 1$ & .588 & .079 & .681 & 7.461 & .000 \\
\hline
\end{tabular}

a. Dependent Variable: $\mathrm{Y}$

Hasil analisis regresi linier sederhana yang telah dilakukan diperoleh nilai a (intersep $\mathrm{Y})=0,527, \mathrm{~B},($ koefisien regresi $\mathrm{X})=0,588$ atau dinyatakan dengan persamaan regresi sebagai berikut:

$$
\mathrm{Y}=\mathbf{0 , 5 2 7}+\mathbf{0 , 5 8 8} \mathrm{X}
$$

Dengan persamaan regresi ini berarti, misalnya jika nilai $\mathrm{X}$ konstan, perubahan nilai 1 poin pada variabel $\mathrm{X}$ akan diikuti juga oleh perubahan nilai pada $Y$ sebesar 0,588 , jika nilai variabel $X$ diasumsikan konstan, setiap perubahan 1 poin pada variabel $X$ akan diikuti dengan perubahan nilai $\mathrm{Y}$ sebesar 0,527. Dengan demikian, secara sendiri variabel $X$ menyebabkan terjadinya perubahan nilai pada $\mathrm{Y}$ sebesar $72,1 \%$. Kesimpulannya hipotesis asosiatif kedua penelitian ini diterima: "Ada pengaruh yang nyata antara kompetensi profesional terhadap kualitas pembelajaran dosen PAI di FKIP Universitas Pattimura Ambon." Dengan adanya pengaruh yang signifikan antara $\mathrm{X}$ terhadap $\mathrm{Y}$, maka besarnya pengaruh kompetensi profesional terhadap kualitas pembelajaran dosen PAI di Universitas Pattimura Ambon adalah:

1. Pengaruh relatif sebesar: $\mathrm{X}=$ $0,580 / 0,849 \times 100 \%=68,36 \%$.

2. Pengaruh efektifnya sebesar: $\mathrm{X}=$ $0,588 / 0,849 \times 72,1 \%=49,93 \%$.

\section{Pengaruh Kompetensi Terhadap Kualitas Pembelajaran Dosen PAI}

Hasil analisis korelasi dan regresi sebagaimana yang telah dijelaskan pada bagian terdahulu menunjukkan bahwa kompetensi dosen PAI memiliki hubungan dan pengaruh yang positif dan signifikan terhadap kualitas pembelajaran dosen PAI di FKIP Unpatti Ambon. Secara teoritis kompetensi dosen PAI yang dimaksud adalah "kompetensi pedagogik, kepribadian, sosial, dan profesional."

Kenyataan ini seejalan pasal 10 ayat 1Undang-Undang Nomor 14 tahun 2005 tentang guru dan dosen, dan pasal 28 ayat 3 Peraturan Pemerintah Nomor 19 tahun 2005 tentang standard pendidikan nasional dijelaskan bahwa pendidikan nasional berfungsi untuk mengembangkan kemampuan dalam membentuk waktu serta kompetensi pendidikan, khusus kompetensi pedagogik dan profesional sebagai elemen kompetensi guru PAI sebagai kajian penelitian.

Kompetensi dosen PAI memiliki hubungan dan pengaruh yang positif dan signifikan terhadap kualitas pembelajaran dosen PAI di FKIP Unpatti Ambon. Besarnya pengaruh yang diberikan adalah: Pengaruh relatif sebesar: $X=0,580 / 0,849 \times 100 \%=$ $68,36 \%$, sedangkan Pengaruh efektifnya sebesar: $X=0,588 / 0,849 \times 72,1 \%=49,93 \%$.

Kompetensi dosen PAI tersebut berkesesuain dengan hasil penelitian dilakukan Syaikhul Alim yakni "pengaruh kualifikasi pendidikan, keikutsertaan diklat dan sikap pada profesi terhadap kompeten tenaga pendidik," hasilnya terdapat pengaruh baik individu maupun bersama-sama dari kualifikasi pendidikan, keikutsertaan diklat dan sikap pada 
profesi terhadap kompetensi tenaga pendidik. Hasil penelitian yang dilakukan Timbul Arifin dan Mutamimah dengan judul "model peningkatan loyalitas dosen melalui kepuasan kerja dosen", variabel dalam penelitian ini sebagai berikut: Kompetensi (X1), Kepemimpinan transformasi (X2), Promosi jabatan (X3), Motivasi (X4) merupakan variabel eksogen, sedangkan Kepuasan(Y1) adalah variabel intervening dan Loyalitas (Y2) adalah variabel Endogen. Kesimpulan bahwa terdapat pengaruh kompetensi, kepemimpinan transformasi, promosi jabatan, motivasi secara individu maupun bersama terhadap kepuasan sedangkan tidak berpengaruh individu kompetensi, kepemimpinan transformasi, promosi jabatan, dan motivasi terhadap loyalitas hanya berpengaruh bersama.

Untuk lebih jelasnya, maka pembahasan terhadap masing-masing elemen kompetensi dosen itu dalam kaitannya dengan peningkatan kualitas pembelajaran dosen PAI.

\section{Pengaruh Kompetensi Profesional Terhadap Kualitas Pembelajaran Dosen PAI}

Hasil penelitian menunjukkan bahwa kompetensi profesional dosen PAI dinilai cukup profesional melakukan proses pembelajaran, karena nilai elemen-elemen kompetensi profesional pada umumnya cukup baik. Cukup profesionalnya dosen PAI melakukan pembelajaran, yang berarti juga cukup baiknya kualitas pembelajaran dosen PAI, ternyata memiliki hubungan dan pengaruh positif dan signifikan terhadap kualitas pembelajaran dosen PAI di FKIP Unpatti Ambon.

Untuk meningkatkan kualitas pembelajaran dosen PAI, maka kompetensi profesional dosen PAI berorientasi pada peningkatan kualitas pembelajaran dosen PAI, artinya dosen PAI memiliki kemampuan dalam pengelolaan proses pembelajaran. Dosen memiliki kemampuan pengetahuan dan keterampilan dalam mengelola pembelajaran. Sebagaimana diungkapkan Zakiah Daradjat bahwa "motivator, fasilitator, organisator, informatori dan konselor berhubungan dengan tanggung jawab dosen." Dosen PAI dalam melaksanakan tugasnya sebagai pendidik dan pembimbing, minimal ada dua fungsi yakni fungsi moral dan fungsi kedinasan. Dosen dengan segala peranannya akan selalu menonjol fungsi moralnya, sebab walaupun dalam situasi kedinasan dosen tidak dapat melepaskan fungsi moralnya.

\section{SIMPULAN DAN SARAN}

Kesimpulan penelitian ini akan menguraikan hasil analisis, pembahasan yang terfokus pada masalah dan tujuan penelitian ini dengan kesimpulan-kesimpulan sebagai berikut.

1. Kompetensi profesional dosen PAI memberikan pengaruh yang positif dan signifikan terhadap kualitas pembelajaran dosen PAI di FKIP Unpatti Ambon yakni 0,849 dimana $r$ hitung 0,849 lebih besar dari $\mathrm{r}$ table 0,202. Semakin baik kompetensi profesional dosen PAI, maka semakin meningkat kualitas pembelajaran dosen PAI di FKIP Unpatti Ambon ditunjukkan dengan koefisien determinasi $\left(r^{2}\right)$ variabel $X$, terhadap $\mathrm{Y}$ sebesar $0,849^{2}=0,7208$ atau $72,1 \%$.

2. Besaranya pengaruh kompetensi profesional terhadap kualitas pembelajaran dosen PAI di FKIP Universitas Pattimura Ambon, mencakup sumbangan relatif, 68,36\% kompetensi profesional, maksudnya responden yang memberikan jawaban "cukup" atas kuesioner pada kompetensi Profesional dosen berkisaran $100 \%$. Sedangkan sumbangan efektif, 49,93\% kompetensi profesional maksudnya responden yang memberikan jawaban "baik/kompeten" atas kuesioner pada kompetensi Profesional dosen.

\section{DAFTAR RUJUKAN}

Abdurrahman, H., Pengelolaan Pengajaran. Cet. V; Ujung Pandang: Bintang Selatan, 1994.

Daradjat, Zakiah et., Metode Khusus Pengajaran Agama Islam Cet. III; Jakarta: Bumi Aksara, 2004.

Fathurrahman, M Pupuh. Sobry Sutikno. Strategi Belajar Mengajar melalui Pemahaman Konsep Umum dan Konsep Islami Cet. I; Bandung: PT. Refika Aditama, 2007.

Satori, Djama'an dan Aan Komariah. Metode Penelitian Kualitatif. Cet. I; Bandung; Alfabeta, 2009.

Sudjana, Nana. Cara Belajar Mahasiswa Aktif dan Proses Belajar Mengajar Cet. III; Bandung: Sinar Baru, 1996. 
Pembelajar: Jurnal Ilmu Pendidikan, Keguruan, dan Pembelajaran. 1 (1) April 2017

Sugiono. Statistik Untuk Penelitian. Bandung: Alpabeta, 1997.

Undang-undang Republik Indonesia No. 14 Tahun 2005 tentang Dosen dan Dosen dan Undang-Undang Republik Indonesia No. 20 Tahun 2003 tentang Sisdiknas Sistem Pendidikan Nasional. Bandung, 2006.

Undang-Undang No. 20 Tahun 2003 Tentang Sisdiknasi, Sistem Pendidikan Nasional. Bandung: Tahun 2006. 